\title{
Transition program (TP) in Hospital Infanta Leonor
}

Sanahuja Muñoz, C; Alonso Cecilia, M; Diez del Corral Belda, M; Rodriguez Quiroga, A; Sanchez Novella, C; Fernandez de Henestrosa, C; Quintero del Álamo, FJ.

\section{OBJECTIVES AND AIMS}

Studies conducted by the International Consortium in Psychiatric Epidemiology (ICPE) have shown that psychiatric disorders, in addition to having a high prevalence, have an early onset age [1]

The transition stage between adolescence and adulthood is a hugely vulnerable period during which the rate of follow-up by patients is much higher than at other ages [2,3] so a design of specific programs is necessary in order to promote the maintenance's treatment.

Transition of care is defined as a planned transfer of adolescents from child and adolescent centers and resources to service-oriented care for adults, in a process that takes into account the medical, psychological and educational needs of young people during this period [4].

\section{METHODS}

A description of the transition program that is being carried out in the mental health department of the hospital Infanta Leonor

\section{RESULTS}

The transition program team consists of a psychiatrist, a clinical psychologist, and a specialized nurse. The follow-up, described here, is done on an outpatient basis for adolescents and young adults (from 14 to 26 years old) with severe mental illness, from the moment of diagnosis to the point of successful transition to adult mental health services

\section{DESCRIPTION OF THE PROCESS}

1, Proposal phase

- Valuation of treatment requests

2, Pre-admission phase:

- First valuation interview

- Team meeting and decision

- Coordination with the requesting specialist

3, Start-to-treatment phase:

- Assess clinical status

- Treatment planning

\section{TREATMENT STEPS}

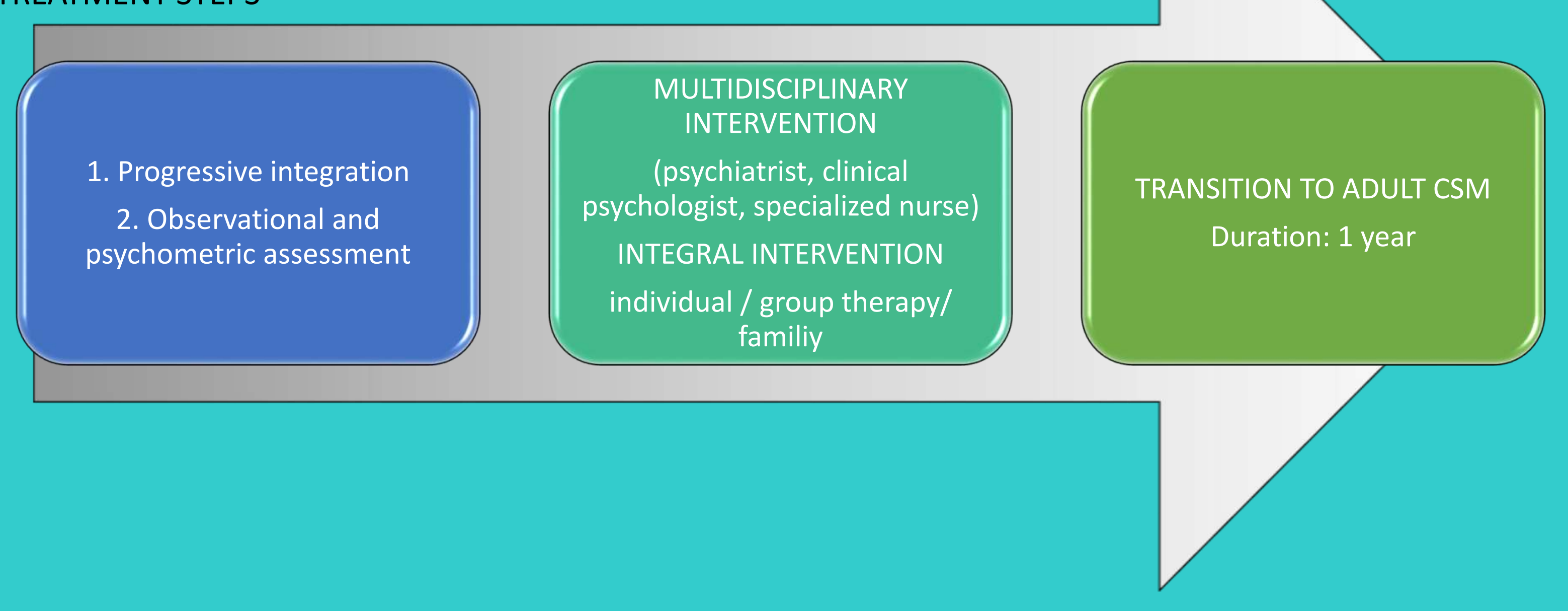

\section{CONCLUSION}

As it is described in the literature, as well as what is observed by the mental health service specialists, there is a strong need for specialized services in the transition period

BIBLIOGRAPHIC REFERENCES

1. Kessler RC, Angermeyer M, Anthony JC, DE Graaf R, Demyttenaere K, Gasquet I et al. Lifetime prevalence and age-of-onset distribution of mental disorder in the WroldHealth Organization's World Mental Health Survey Initiative. World Psychiatry.

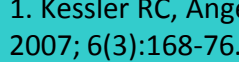

2.McGorry PD, Hickie IB, Yung AR, Pantelis C, Jackson HJ. Clinical staging of psychiatric disorders: a heuristic framework for choosing earlier, safer and more effective interventions. Aust N Z J Psychiatry. 2006; 40(8):616-22. 3. Singh SP, Paul M, Ford T, Kramer T, Weaver T, McLaren S et al. Process, outcome and experience of transition from child to adult mental healthcare: multiperspective study. Br J Psychiatry. 2010; 197(4):305-12. 